\title{
Estimation of hydraulic parameters by using VES sounding and neural network techniques in the semi-arid Khanasser valley region, Syria
}

\author{
Jamal ASFAHANI*, Zuhair AHMAD \\ Atomic Energy Commission of Syria, \\ P.O. Box 6091, Damascus, Syria
}

\begin{abstract}
An alternative approach based on using Vertical Electrical Sounding (VES) measurements and Artificial Neural Network (ANN) technique is newly proposed for computing the hydraulic conductivity $K$ and the transmissivity $T$ of an aquifer. VES measurements in the locations, where available water samples exist are required in such an approach, in order to train a neural network with fitting capability to evaluate both the hydraulic conductivity and transmissivity. The hydraulic conductivity and transmissivity are thereafter extrapolated by the use of trained neural network, even in the VES points where no water samples exist. This approach is practiced and tested in the Khanasser valley, Northern Syria, where the hydraulic conductivity and the transmissivity of the Quaternary aquifer is computed. We find an acceptable agreement between the hydraulic conductivity values obtained by the new approach and those obtained by the pumping test, which range between 0.864 and $8.64 \mathrm{~m} /$ day.
\end{abstract}

Key words: Hydraulic conductivity, Transmissivity, VES Sounding, Khanasser Valley, Syria

\section{Introduction}

The aquifer behaviour during the different stages of water extraction is predicted by the groundwater modelling by the use of the hydraulic conductivity parameter, considered as the most important in hydrogeology. The pumping tests technique is traditionally applied to estimate the hydraulic conductivity, but this technique is affected being expensive and yields to low spare resolution maps.

Geophysical methods are largely used to develop alternative approaches, aimed at estimating the hydraulic parameter, where specific relationships

\footnotetext{
*corresponding author: e-mail: cscientific@aec.org.sy (J. Asfahani)
} 
between hydro-geological and geophysical parameters are provided (Heigold et al., 1979; Frohlich, 1994; Frohlich et al., 1996; Yadav and Abolfazli, 1998; Salem, 1999; De Lima and Niwas, 2000; Niwas and De Lima, 2003; Dhakate and Singh, 2005; Lesmes and Friedman, 2005; Asfahani, 200\%a,b,c; Asfahani, 2010a,b; Arétouyap et al., 2015; Arétouyap et al., 2019a; Arétouyap et al., 2019b).

We propose in this paper a new practical technique based on the application of vertical electrical sounding (VES) and ANN techniques to estimate the aquifer hydraulic conductivity and transmissivity.

The application of VES technique offers different advantages in comparing with the traditional pumping tests technique. Accordingly, we do not need a ground perforation, where faster information regarding the hydraulic conductivity distribution is obtained with high resolution maps, by the use of dense VES sounding points.

The new proposed neural networks approach takes into consideration only the groundwater salinity, for characterizing the Quaternary aquifer hydraulic conductivity and transmissivity in the semi-arid Khanasser valley region, Northern Syria, Fig. 1.

The ability of ANN as universal function approximator is used in this paper to provide a data-driven approximation of the relation between hydraulic conductivity and hydraulic transmissivity and the saturated aquifer resistivity and the saturated thickness of the Quaternary aquifer. This requires the hydraulic conductivity and transmissivity measurements using pumping tests, which are expensive and complex to operate. Four pumping tests are only available in this work (Asfahani, 2016), which are not sufficient to train ANN. The recent computed values of hydraulic conductivity and transmissivity based on VES measurements (Asfahani, 2016), and the measured available four pumping test values are therefore used to train ANN.

Geophysical researches have been practiced in the Khanasser Valley through an international research program, directed by three scientific organizations; Bonne University, Germany, International Center for Agriculture Research in the Dry Areas (ICARDA), and Syrian Atomic Energy Commission (Schweers et al., 2002). The specific problems related to the marginal dry-land environments were solved by this research program.

Livelihoods, the diversity and dynamics of the natural resources, poverty and the relative easy accessibility made Khanasser as a prime candidate. 


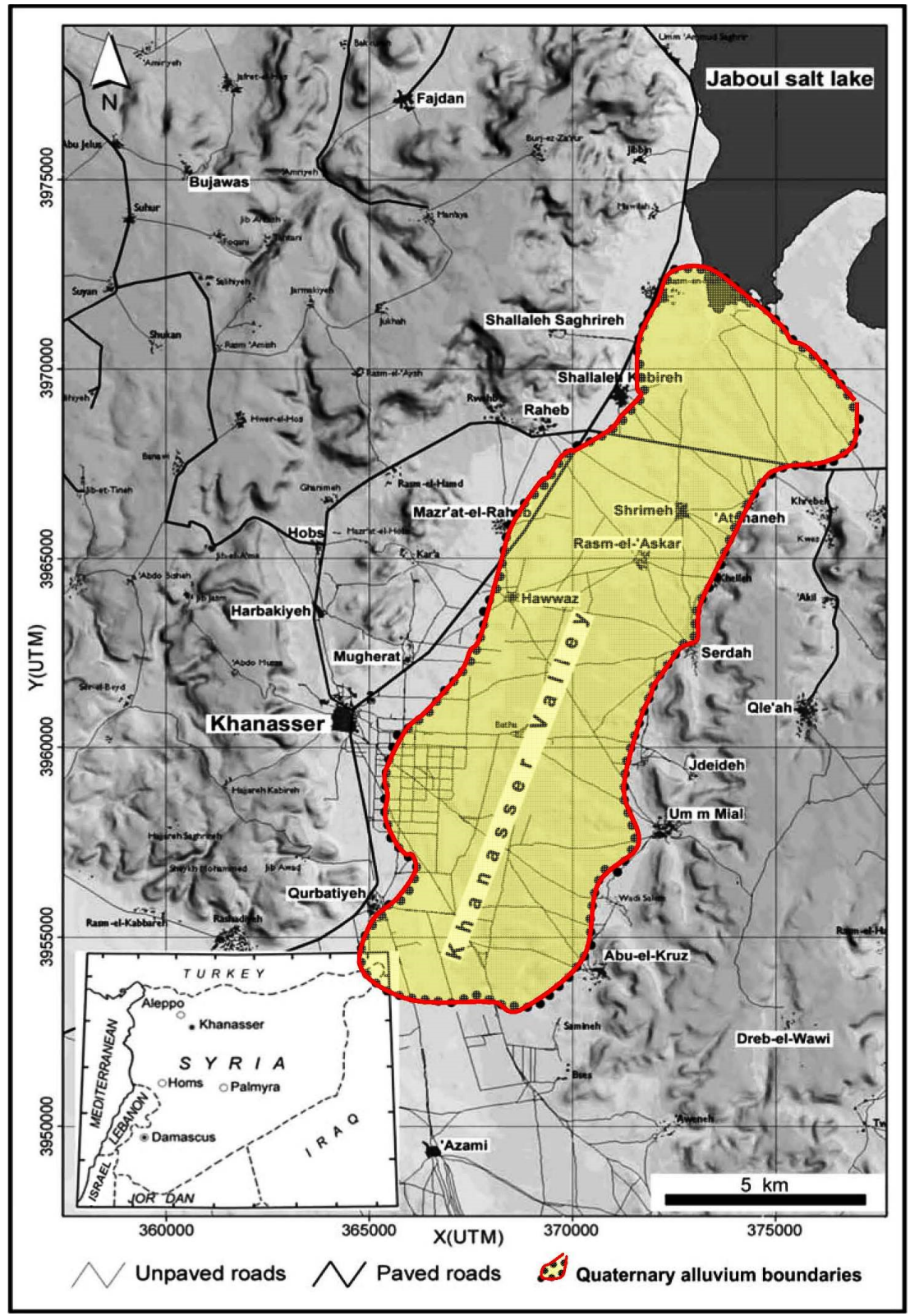

Fig. 1. Location of Khanasser valley, Northern Syria. 
The rainfall in the Khanasser region is low and unpredictable, while the natural resources are quite poor and prone to degradation. Annual rainfall ranges between 200 and $250 \mathrm{~mm} /$ year, but the annual rainfall extremes between 1957 and 2001 were 93 and $393 \mathrm{~mm}$ (Soumi, 1991).

\section{Hydrogeology of the Khanasser Valley}

Khanasser Valley study area lies between two hill ranges; the Jabal Shbeith in the east and the Jabal Al Hoss in the west, and is located approximately $70 \mathrm{~km}$ southeast of Aleppo City. The drainage of the northern part of the valley is towards the Jaboul salt lake, while the drainage of the southern part is towards the Adami depression in the south, (Figs. 1 and 2). Fig. 3 shows a geological cross-section along the transverse geoelectrical profile TP5.

The groundwater extraction in the Khanasser Valley is achieved through three aquifers. The deepest one related to upper Cretaceous is at $400 \mathrm{~m}$ below ground level. The second one is the Paleocene-Lower Eocene limestone aquifer of a low productivity $(A C S A D, 1984)$, its average hydraulic conductivity $(k)$ is $0.0054 \mathrm{~m} /$ day as referred from the pumping test (Schweers et al., 2002). A hydraulic conductivity ranging between $0.008 \mathrm{~m} /$ day and $0.5 \mathrm{~m} /$ day for the Paleogene formation was already revealed by Lengiprovodkhoz Institute (1987).

In the central part of Khanasser valley, the paleogene strata are not very thick; about $50 \mathrm{~m}$ of lower Eocene and Paleocene are found above the Maestrichtian. The most transmissive third aquifer in the region is the Quaternary water bearing formations, that are situated near the surface, and covered by some of $10 \mathrm{~m}$ of alluvial and proluvial soil. The direct recharge from rainwater as well as infiltrating runoff and subsurface flow from the slopes of Jabal Al Hoss and Jabal Shbeith are the main source for this aquifer. The substantial increase in groundwater withdrawal from the upper, unconfined aquifer system observed during the last two decades is due to the rapid development of motorized irrigation wells. Khanasser valley might be affected by salt water intrusion from the Jaboul salt lake as indicated by the analysis and the groundwater monitoring, where considerable changes in quality and water level are observed since 1998 (Hoogeveen and Zobisch, 1999). 


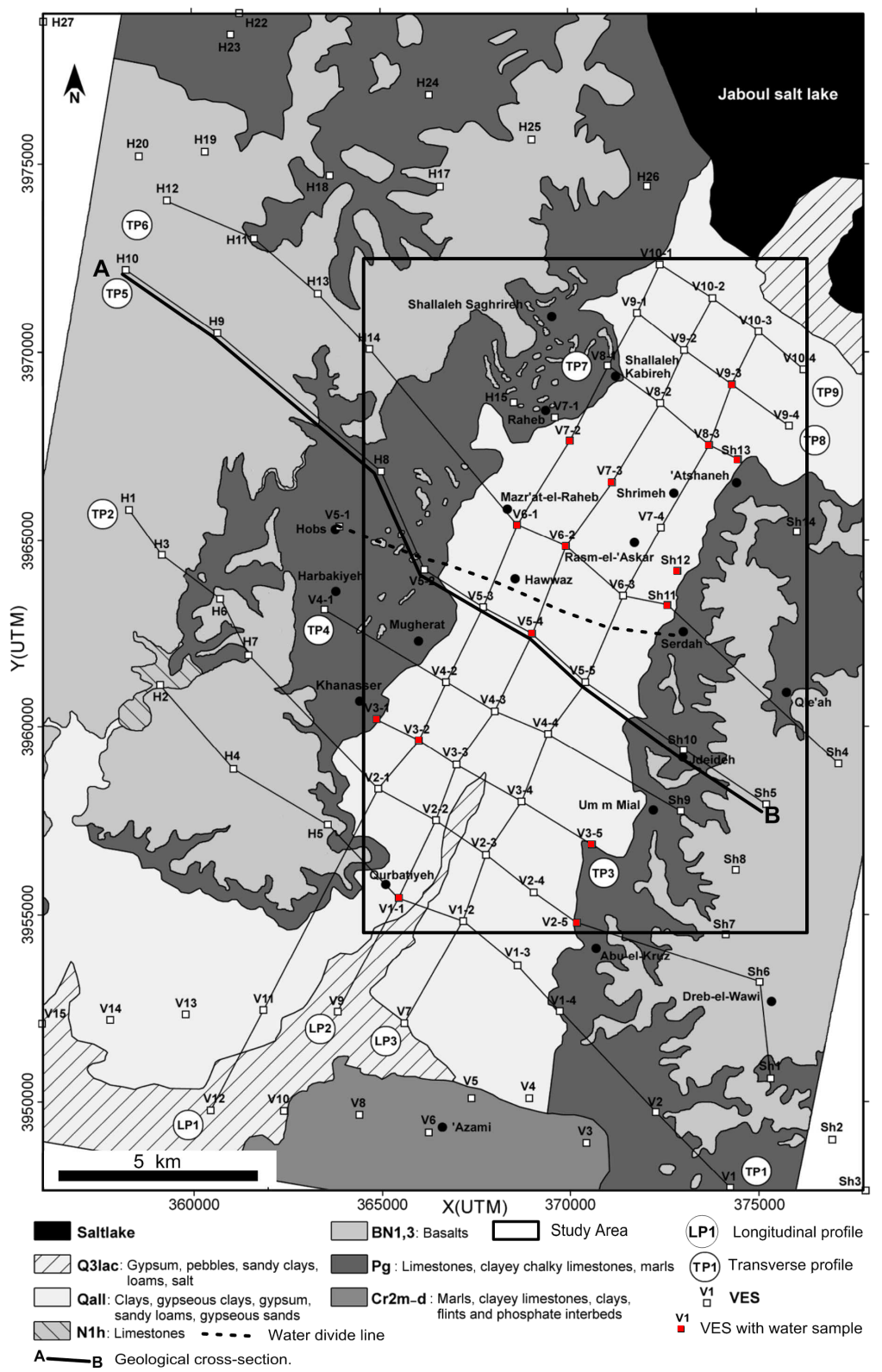

Fig. 2. Geological map of Khanasser valley and its surroundings (after Ponikarov and Mikhailov, 1964), with the locations of VES soundings (Asfahani, 2016). 


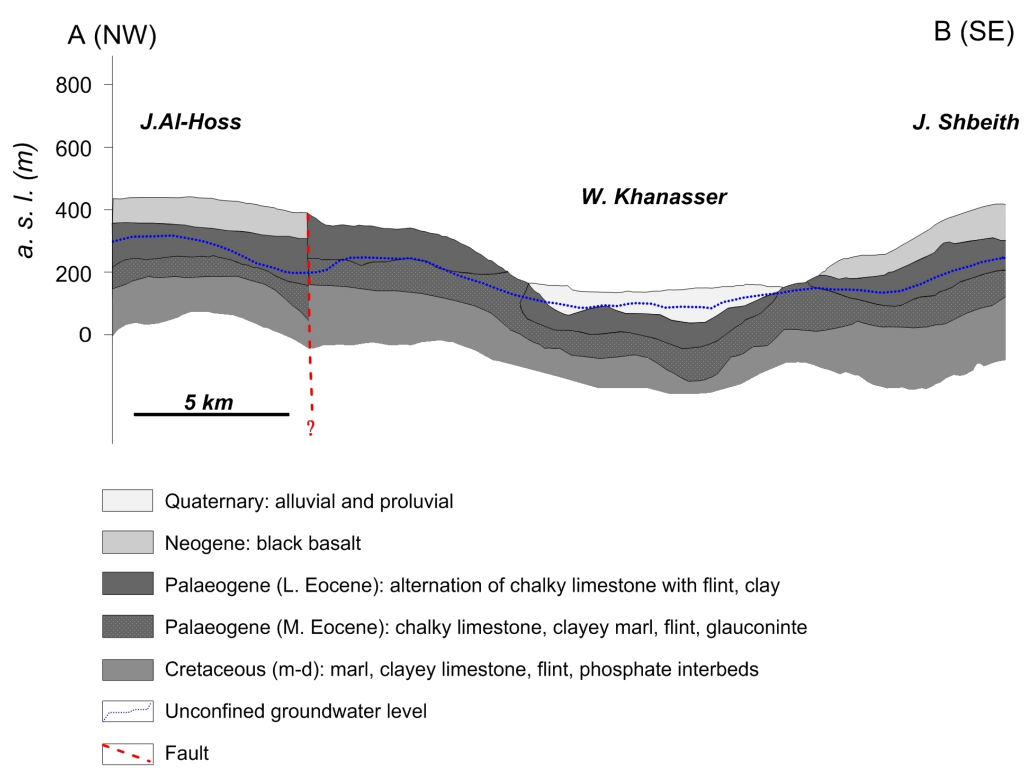

Fig. 3. Geological cross-section along the transverse geoelectrical profile TP5 (Asfahani, 2013).

\section{VES measurements and interpretation}

Schlumberger configuration was used during the Khanasser Valley research program to carry out ninety-six vertical electrical resistivity soundings VES, where their locations are shown on Fig. 2 (Asfahani, 2010a, and Asfahani, 2007a).

The AB/2 current electrode spacing was ranged for all the VES soundings between a minimum of $3 \mathrm{~m}$ and a maximum of $500 \mathrm{~m}$.

The two current electrodes (A and B) are symmetrically expanded about the centre of the spread, while the potential electrodes ( $\mathrm{M}$ and $\mathrm{N}$ ) remain fixed. The apparent resistivity $(\varrho a)$ for a given position of the current and potential electrodes is written by the following equation:

$\rho a=\frac{2 \pi}{\frac{1}{A M}-\frac{1}{B M}-\frac{1}{A N}+\frac{1}{B N}} \frac{\Delta V}{I}$,

where $I$ is the current introduced into the earth, $\Delta V$ is the potential dif- 
ference between the potential electrodes, and $A M, B N, A N$ and $B N$ are interelectrodic spacing.

Curve matching technique with the use of master curves is practiced to interpret the field resistivity curves (Orellana and Mooney, 1966), and to get the initial determination of resistivities and thicknesses of corresponding layers (initial approximate model). An inverse technique program is thereafter used to correctly interpret the initial model parameters, until a goodness of fit between the resistivity field curve and the computed regenerated curve is obtained (Zohdy, 1989; Zohdy and Bisdorf, 1989). The one-dimensional medium 1D is assumed in the studied Khanasser region.

Fig. 4 shows a field VES example at the point V10-4 and its 1D interpretative model.

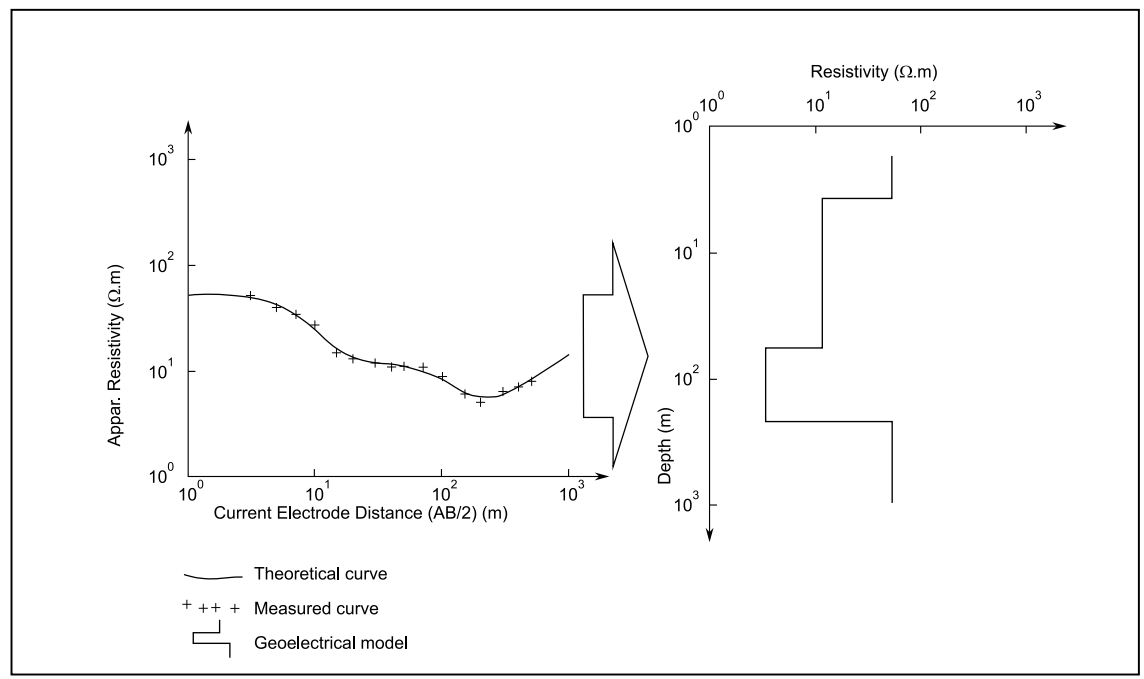

Fig. 4. Field VES example and its 1D interpretation at the location V10-4.

The 1D quantitative interpretations of these ninety six VES, distributed on the twelve profiles, (both transverse and longitudinal) enabled (Asfahani, $200 \%$ a) identification of both the geometry of the Khanasser Valley and the geoelectrical characteristics of Quaternary, Paleogene and Maistrechtian deposits. Fig. 5 presents the geoelectrical interpretative section established for the VES distribution along the TP5 transverse profile (TP5 corresponds to the geological section shown in Figs. 2 and 3), which shows the resistivity 


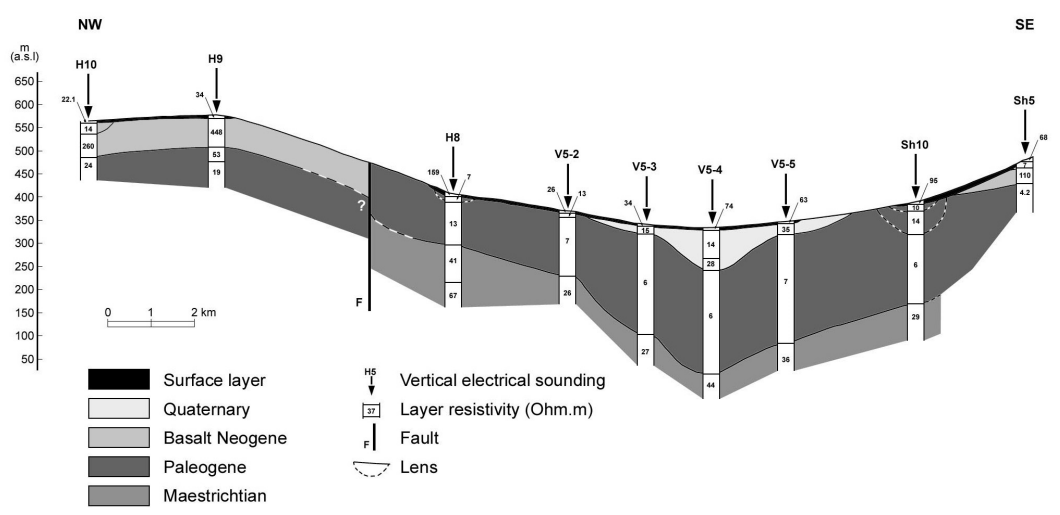

Fig. 5. Geoelectrical interpretation along TP5 (Asfahani, 2013).

and thickness values of the Quaternary and Paleogene aquifers.

Asfahani (2007a) has indicated to the presence of two main geological structures, one in the north and the other in the south of the line joining the towns of Hobs and Sirdah. This observation has been confirmed for all the geoelectrical maps corresponding to different spacings $\mathrm{AB} / 2$ (from $3 \mathrm{~m}$ to $500 \mathrm{~m}$ ), revealing that a clear deep tectonic effect is present along this joining line.

\section{Artificial Neural Networks}

An Artificial Neural Network (ANN), like their biological analogues consists of a number of interconnected processing neurons, which are logically arranged in several layers that interact with each other through weighted connections. ANN can be used as mathematical tools that have found several applications in a wide range of research areas (Basheer and Hajmeer, 2000). Moreover, it has been proven theoretically that multilayer feedforward networks called Multi Layer perceptron (MLP) are universal approximators (Hornik et al., 1989; Hornik, 1991).

A MLP consists of an input layer, an output layer and several hidden layers. Node in a MLP network is called a neuron as shown in Fig. 6. It includes a summer and a nonlinear activation function $g$. The number of neurons in each layer and the number of layers in the network depend on the nature of the problem. The number of hidden nodes is a critical parameter 
of any MLP. Too many nodes may cause over fitting the data, thus resulting in poor generalization on data not used for training. On the other hand, too few hidden nodes will cause under fitting of the model, which will therefore be insufficiently accurate. Most of the mathematics behind the connections and processing within the nodes are in fact linear combinations (Basheer and Hajmeer, 2000).

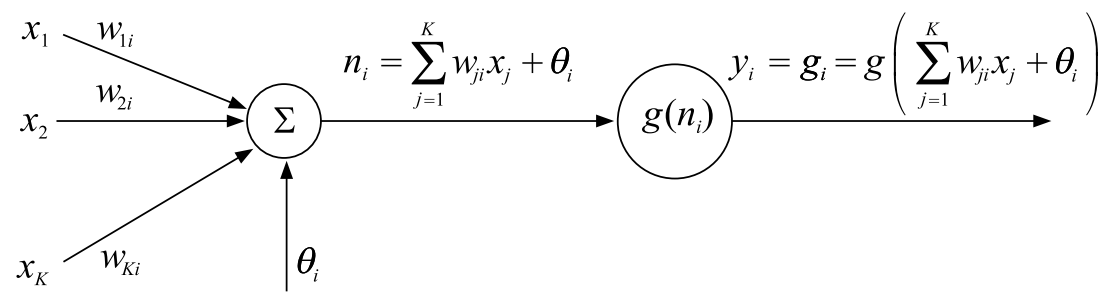

Fig. 6. Single neuron model.

The inputs $x_{k}, k=1, \ldots, K$ to the neuron are multiplied by scalar weights $w_{k i}$ and summed up together with the constant bias term $\theta_{i}$. The scalar weights determine the nature and strength of the influence between the interconnected neurons. Each neuron is connected to all the neurons in the next layer. The resulting $\eta_{i}$ is the input to the activation function $g$. The activation function was originally chosen to be a relay function, but for mathematical convenience a hyperbolic tangent (tanh) or a sigmoid function are most commonly used.

The output of node $i$ becomes:

$y_{i}=g\left(\sum_{j=1}^{K} w_{j i} x_{j}+\theta_{i}\right)$.

A MLP network is formed by connecting of several nodes in parallel and series, where a typical network is shown in Fig. 7.

The output $y_{i}$ of the network becomes:

$y_{i}=g\left(\sum_{j=1}^{3} w_{j i}^{2} g\left(n_{j}^{1}\right)+\theta_{j}^{2}\right)=g\left(\sum_{j=1}^{3} w_{j i}^{2} g\left(\sum_{k=1}^{K} w_{j i}^{1} x_{k}+\theta_{j}^{1}\right)+\theta_{j}^{2}\right)$.

From (2) we can conclude that a MLP network is a nonlinear parameterized map from input space $\mathbf{X}$ to output space $\mathbf{Y}$. The parameters are the 


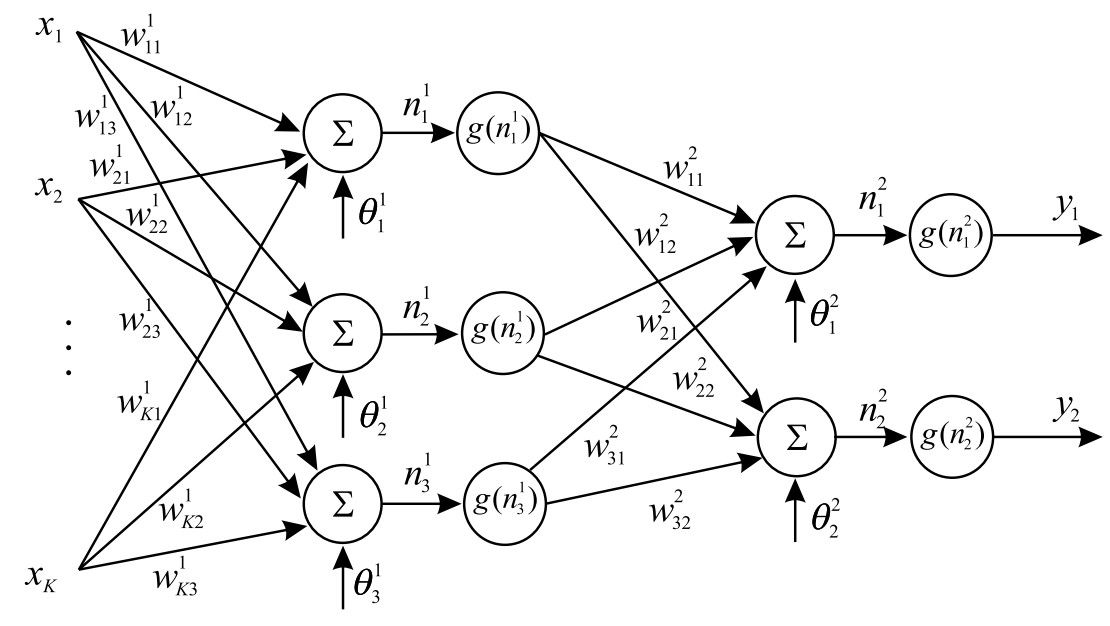

Input layer

Hidden layer

Output layer

Fig. 7. A network with one hidden layer.

weights $w_{i j}^{k}$ and the biases $\theta_{j}^{k}$. Activation functions $g$ are assumed to be the same in each layer and known in advance. The same activation function $g$ in the figure is used in all layers.

Given input-output data $\left(x_{i}, y_{i}\right), i=1,2, \ldots, N$ finding the best MLP network is formulated as a data fitting problem. The parameters to be determined are $\left(w_{i j}^{k}, \theta_{j}^{k}\right)$.

The procedure functions as follows; the designer has to fix the structure of the MLP network architecture and the number of hidden layers and neurons (nodes) in each layer. The activation functions for each layer are selected and assumed to be known at this stage. The weights and biases are the unknown parameters to be estimated.

Several algorithms exist for determining the network parameters. The algorithms in neural network literature are called learning or teaching algorithms, and belong to parameter estimation algorithms in the system identification.

The most well-known are back-propagation and Levenberg-Marquardt algorithms. Back-propagation is a gradient based algorithm, which has many variants. Levenberg-Marquardt is usually more efficient, but needs more computer memory. We will concentrate herein only on using the teaching 
algorithms. The procedure of teaching algorithms for multilayer perceptron networks is summarized as follows:

1. At first the structure of the network is defined. Activation functions are chosen in the network, where the network parameters of weights and biases are initialized.

2. The parameters associated with the training algorithm as error goal, maximum number of epochs (iterations), etc, are defined.

3. The training algorithm is called.

After determining the neural network, the result is first tested by simulating the output of the neural network with the measured input data. This is compared with the measured outputs. Final validation must be carried out with independent data.

\section{Application to hydraulic parameters estimation}

As mentioned in section 2, ANN act as universal function approximators. This makes them useful in modelling problems in which the relation between dependent and independent variables is poorly understood. The ability of ANN is used in this paper to provide a data-driven approximation of the relation between hydraulic conductivity $K$ and the saturated aquifer resistivity $\rho_{\text {rock }}$ and the saturated thickness of the Quaternary aquifer $h$ and between transmissivity $T$ and $\rho_{\text {rock }}$ and $h$ as illustrated in Fig. 8 .

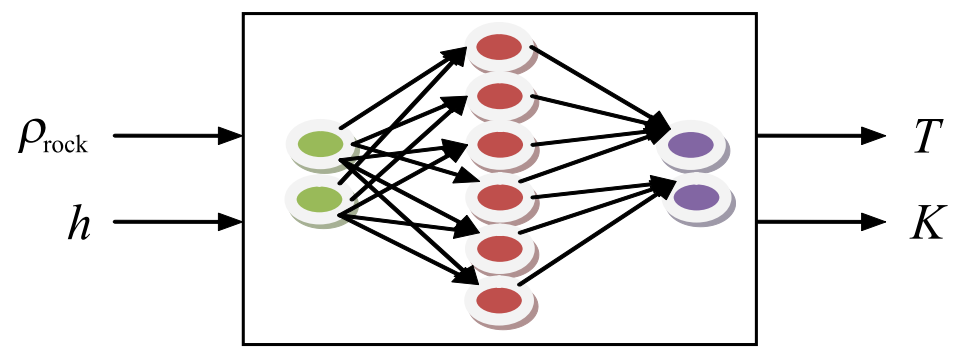

Fig. 8. Black box model of ANN used in this work.

Applying ANN requires the measurement of hydraulic conductivity and transmissivity using pumping tests which are expensive and complex to operate. Four pumping tests are only available in this work (Asfahani, 2016), 
which are not sufficient to train ANN. The computed values of hydraulic conductivity and transmissivity based on VES measurements, recently obtained by Asfahani (2016) and additional four available pumping test measured values are therefore used to train ANN.

The proposed approach described herewith based on Artificial Neural Network is established as follows:

1. Firstly, carry out VES measurements in the locations where water samples related to Quaternary aquifer are available to evaluate the water resistivity $\rho_{w}$. Fifteen VES measurements have been measured and identified as close to the water sample locations. Those 15 VES soundings have been interpreted quantitatively, where the resulting resistivity and thickness of the saturated Quaternary aquifer $\left(\rho_{\text {rock }}\right.$ and $\left.h\right)$ are shown in Table 1 (Asfahani, 2016).

2. Determine the formation factor $F$ used in Archie's law 1942 (Archie, 1942).

3. Compute the corresponding hydraulic conductivity $K$ by using Salem's formula 2001 (Salem, 2001; Asfahani, 2016).

4. Compute the aquifer transmissivity $T$ by knowing of the average $\bar{K}$ of hydraulic conductivity and $h$.

5. Train an artificial neural network using the data computed in step 2, 3, 4 and shown in Table 1.

6. Secondly, carry out VES measurements in the locations where no water samples exist.

7. Use the neural network trained in step 5 to extrapolate the hydraulic conductivity $K$ and transmissivity $T$ in VES locations, even where no water samples exist.

The formation factor $F$ used in Archie's law in its general form is computed as the ratio of $\rho_{\text {rock }}$ and $\rho_{w}$ as follows:

$F=\frac{\rho_{\text {rock }}}{\rho_{w}}$,

where $\rho_{\text {rock }}$ is the saturated aquifer resistivity estimated from the quantitative interpretation of (VES), and $\rho_{w}$ is the pore fluid resistivity. Water resistivity $\rho_{w}$ is obtained through converting water conductivity. 
Salem's formula 2001 which takes only the groundwater salinity into consideration relates hydraulic conductivity $K$ with formation factor $F$ obtained by using VES method. It is applied to obtain the hydraulic conductivity $K$ as follows:

$K=0.66528 * F^{2.09}$.

The following equation is used to compute the transmissivity $T$ for the interpreted fifteen VES as follows:

$T=\bar{K} * h$,

where $\bar{K}$ is the average of hydraulic conductivity of the available fifteen water samples shown in Table 1.

\section{Results and discussion}

MATLAB Neural Network Toolbox is used to create and train ANN with fitting capability to evaluate the hydraulic conductivity and transmissivity (MATLAB 2009). The MATLAB commands used in the procedure are newff, train and sim. The train procedure requires measured input and measured outputs data. The measured inputs in this work are the resulting thickness and resistivity of the saturated Quaternary aquifer ( $\rho_{\text {rock }}$ and $h$ ) shown in Table 1, while the measured outputs are the computed values of $K$ and $T$ in the 15 VES locations, where water samples related to Quaternary aquifer are available.

Four available measured values of $K$ using pumping test are used instead of the calculated $K$ of VES ones at VES locations of V1-1 (at the locations of Qurbatieh), V3-1 (Khanasser), V5-4 (Batha), and V6-2 (Rasm Askar), where the hydraulic conductivity were $1.55 \mathrm{~m} /$ day, $4.4 \mathrm{~m} /$ day, $6.56 \mathrm{~m} /$ day, and $54.4 \mathrm{~m} /$ day respectively (Schweers et al., 2002).

The training error of the ANN is shown in Fig. 9. The goal error is reached after 600 training epoch and the performance is quite acceptable.

The results shown in Table 1 are used for applying the developed approach, and for training an ANN. The average aquifer water resistivity $\rho_{w}$ of the 15 water samplings is $3.35 \Omega$.m. It is rather used for computing the formation factor $F$ expressed in Eq. (3). 


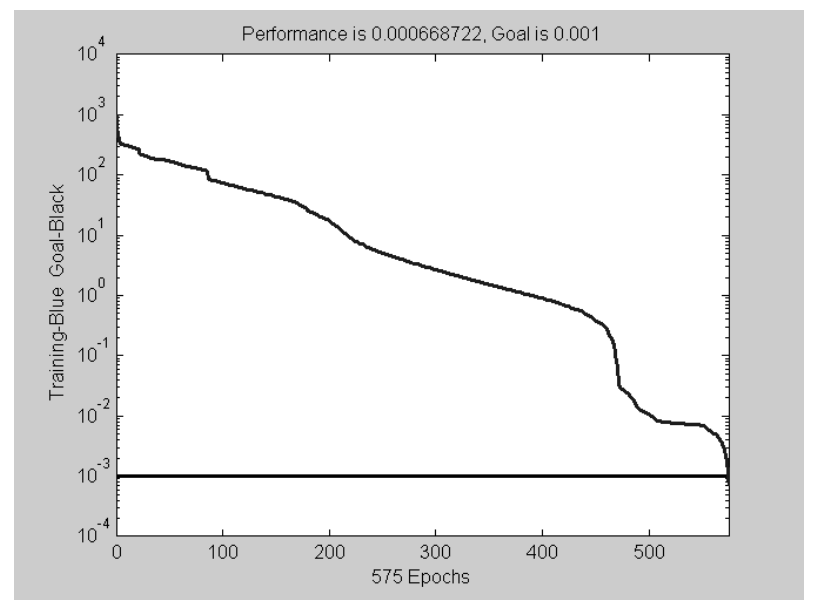

Fig. 9. Training error convergence.

Figs. 10a and 10b show the variations of both resistivity $\rho$ and thickness $h$ of the Quaternary aquifer for the 34 VES locations (15 VES with water samples and 19 VES without water samples) in the Khanasser valley.

Table 1. Data used to train ANN.

\begin{tabular}{|c|c|c|c|c|c|c|}
\hline Location & $\begin{array}{c}\rho_{w} \\
(\Omega . \mathrm{m})\end{array}$ & $\begin{array}{l}\rho_{\text {rock }} \\
(\Omega . \mathrm{m})\end{array}$ & $\begin{array}{c}h \\
(\mathrm{~m})\end{array}$ & $\begin{array}{c}K \\
(\mathrm{~m} / \text { day })\end{array}$ & $\begin{array}{c}K^{*} \\
(\mathbf{m} / \text { day })\end{array}$ & $\begin{array}{c}T \\
\left(\mathrm{~m}^{2} / \text { day }\right)\end{array}$ \\
\hline V6-1 & 3.03 & 8.5 & 12 & 4.65 & & 165.6 \\
\hline V9-3 & 1.3 & 11 & 22.5 & 7.98 & & 310.5 \\
\hline V2-5 & 2.16 & 9.6 & 23.8 & 6 & & 328.44 \\
\hline V1-1 & 1.79 & 6.5 & 31.4 & 2.65 & 1.55 & 433.32 \\
\hline Sh11 & 2.506 & 30 & 31.9 & & & 440.22 \\
\hline Sh12 & 7.44 & 15.5 & 25 & 16.3 & & 345 \\
\hline Sh13 & 4.52 & 9 & 10 & 5.25 & & 138 \\
\hline V8-3 & 3.47 & 17 & 11.5 & 19.82 & & 158.7 \\
\hline V3-1 & 6.85 & 10 & 7.7 & 6.54 & 4.4 & 106.26 \\
\hline V3-2 & 6.02 & 15 & 25 & 15 & & 345 \\
\hline V7-2 & 4.33 & 16 & 6 & 17.5 & & 82.8 \\
\hline V7-3 & 3.03 & 16 & 5.7 & 17.5 & & 78.66 \\
\hline V3-5 & 1.67 & 19 & 12.9 & 25 & & 178.02 \\
\hline V5-4 & 1.2 & 14 & 59 & 13 & 6.56 & 814.2 \\
\hline V6-2 & 1 & 23 & 17.2 & 37 & 54.4 & 237.36 \\
\hline
\end{tabular}

$K^{*}$ is the pumping test value. 
The hydraulic conductivity estimated according to Salem formula varies between a minimum of $2.65 \mathrm{~m} /$ day at VES location V1-1 and a maximum of $37 \mathrm{~m}$ /day at VES location V6-2 with an average of $13.8 \mathrm{~m}$ /day and a standard deviation of $9.4 \mathrm{~m} /$ day. The transmissivity is evaluated by using Eq. (5), and by using an average $\bar{K}$ of $13.8 \mathrm{~m} /$ day. It varies between a minimum of $79 \mathrm{~m}^{2} /$ day at the VES location V7-3 and a maximum of $814 \mathrm{~m}^{2} /$ day at the VES location V5-4 with an average of $277 \mathrm{~m}^{2} /$ day.

The application of the resulting trained ANN allows obtaining $K$ and $T$ in nineteen VES points, where no water samples exist. This is done to characterize as a first approximation the Quaternary aquifer in the Khanasser valley (Table 2 ). The conductivity and transmissivity values shown in Table 2 are directly obtained by using the trained ANN. $E_{K}$ and $E_{T}$ in the Table 2 are the absolute difference between $K$ and $T$ values computed using ANN and those computed using the approach proposed in (Asfahani, 2016). $E_{K}$

Table 2. Calculated hydraulic conductivity $K$ and transmissivity $T$ by ANN, in VES locations where no water samples exist.

\begin{tabular}{|c|c|c|c|c|c|c|}
\hline Location & $\begin{array}{c}h \\
(\mathbf{m})\end{array}$ & $\begin{array}{l}\rho_{\text {rock }} \\
(\Omega . \mathrm{m})\end{array}$ & $\begin{array}{c}K \\
\text { (m/day) }\end{array}$ & $\begin{array}{c}T \\
\left(\mathbf{m}^{2} / \text { day }\right)\end{array}$ & $E_{K}$ & $E_{T}$ \\
\hline V10-4 & 53 & 12 & 7.43 & 396.88 & 0.84 & 41.66 \\
\hline V10-3 & 18 & 7 & 10.67 & 207.74 & 0.03 & 15.05 \\
\hline V10-1 & 34 & 10 & 8.65 & 312.68 & 0.05 & 16.83 \\
\hline V10-2 & 40 & 15 & 10.52 & 386.57 & 0 & 34.61 \\
\hline V9-1 & 21 & 15 & 13.08 & 276.26 & 0.43 & 7.54 \\
\hline V9-2 & 50 & 4.3 & 5.22 & 207.60 & 0.51 & 27.99 \\
\hline V9-4 & 21 & 9 & 8.62 & 173.93 & 2.00 & 49.13 \\
\hline V8-2 & 16.7 & 11 & 13.76 & 242.24 & 0.56 & 21.74 \\
\hline V6-3 & 35 & 17 & 13.03 & 397.05 & 1.07 & 21.72 \\
\hline V5-3 & 15 & 15 & 17.19 & 248.28 & 1.17 & 7.87 \\
\hline V5-5 & 14 & 36 & 28.31 & 383.68 & 1.54 & 8.77 \\
\hline V4-3 & 4.5 & 22 & 40.08 & 180.05 & 0.16 & 0.38 \\
\hline V3-3 & 19 & 15 & 15.12 & 242.29 & 0.95 & 27.04 \\
\hline V3-4 & 11.8 & 26 & 25.05 & 253.33 & 1.34 & 26.51 \\
\hline V2-1 & 15 & 43 & 28.76 & 426.29 & 0.76 & 16.59 \\
\hline V2-2 & 9 & 6.6 & 17.16 & 141.53 & 0.68 & 19.05 \\
\hline V2-3 & 8.5 & 8 & 18.80 & 147.33 & 0.58 & 17.40 \\
\hline V2-4 & 14 & 11.5 & 12.75 & 240.41 & 2.21 & 30.85 \\
\hline V1-2 & 58 & 10 & 6.92 & 413.83 & 0.17 & 2.29 \\
\hline
\end{tabular}


varies between a minimum of 0 , and a maximum of $2.21 \mathrm{~m} /$ day, with an average of $0.97 \mathrm{~m} /$ day and a standard deviation of $0.64 \mathrm{~m} /$ day. $E_{T}$ varies between a minimum of $0.38 \mathrm{~m}^{2} /$ day and a maximum of $49.13 \mathrm{~m}^{2} /$ day, with an average of $20.68 \mathrm{~m}^{2}$ /day and a standard deviation of $12.87 \mathrm{~m}^{2} /$ day.

The hydraulic conductivity values $K$ for the 19 VES points vary between a minimum of $5.22 \mathrm{~m} /$ day at VES location V9-2, and a maximum of $40.08 \mathrm{~m} /$ day at VES location V4-3, with an average of $15.85 \mathrm{~m}$ /day and a standard deviation of $9.00 \mathrm{~m} /$ day.

The transmissivity values for the 19 VES vary between a minimum of $141.53 \mathrm{~m}^{2}$ /day at VES location V2-2, and a maximum of $426 \mathrm{~m}^{2} /$ day at VES location V2-1, with an average of $277.79 \mathrm{~m}^{2} /$ day and a standard deviation of $95.56 \mathrm{~m}^{2} /$ day. Table 3 shows the statistical results of $K$ and $T$ for the 19 VES points obtained by using ANN technique.

Table 3. statistical parameters using 19 VES points with no water samples.

\begin{tabular}{|c|c|c|c|c|c|c|}
\hline & $\begin{array}{c}\boldsymbol{h} \\
(\mathbf{m})\end{array}$ & $\begin{array}{c}\boldsymbol{\rho}_{\text {rock }} \\
(\boldsymbol{\Omega . m})\end{array}$ & $\begin{array}{c}\boldsymbol{K} \\
(\mathbf{m} / \text { day })\end{array}$ & $\begin{array}{c}\boldsymbol{T} \\
\left(\mathbf{m}^{\mathbf{2}} / \mathbf{d a y}\right)\end{array}$ & $\boldsymbol{E}_{\boldsymbol{K}}$ & $\boldsymbol{E}_{\boldsymbol{T}}$ \\
\hline Min & 4.5 & 4.3 & 5.22 & 141.53 & 0 & 0.38 \\
\hline Max & 59 & 43 & 40.08 & 426.29 & 2.21 & 49.13 \\
\hline Average & 22 & 14.8 & 15.85 & 277.79 & 0.79 & 20.68 \\
\hline SD & 15 & 8.5 & 9.00 & 95.56 & 0.64 & 12.87 \\
\hline
\end{tabular}

The hydraulic conductivity values $K$ for the total of thirty four VES points (15 VES with water samples, and 19 VES with no water samples) vary between a minimum of $1.55 \mathrm{~m} /$ day at the VES location V1-1, and a maximum of $54.4 \mathrm{~m} /$ day at the VES location V6-2, with an average of $15.24 \mathrm{~m} /$ day and a standard deviation of $11 \mathrm{~m} /$ day as shown in Fig. 10c.

The transmissivity values for the total of thirty four VES points (15 VES with water samples, and 19 VES with no water samples) vary between a minimum of $78.66 \mathrm{~m}^{2} /$ day at the VES location V7-3, and a maximum of $814.2 \mathrm{~m}^{2}$ /day at the VES location V5-4, with an average of $277.65 \mathrm{~m}^{2} /$ day and a standard deviation of $143.58 \mathrm{~m}^{2}$ /day as shown in Fig. 10d.

The established transmisivity map (Fig. 10d) clearly indicates a distinct transmissive structure at the south of Hobs-Sirdah joining line delineated by (Asfahani, 2007a). It is low at the north of this joining line and increases towards the Sabkha.

The geophysical and hydrogeological parameters computed for the Qua- 


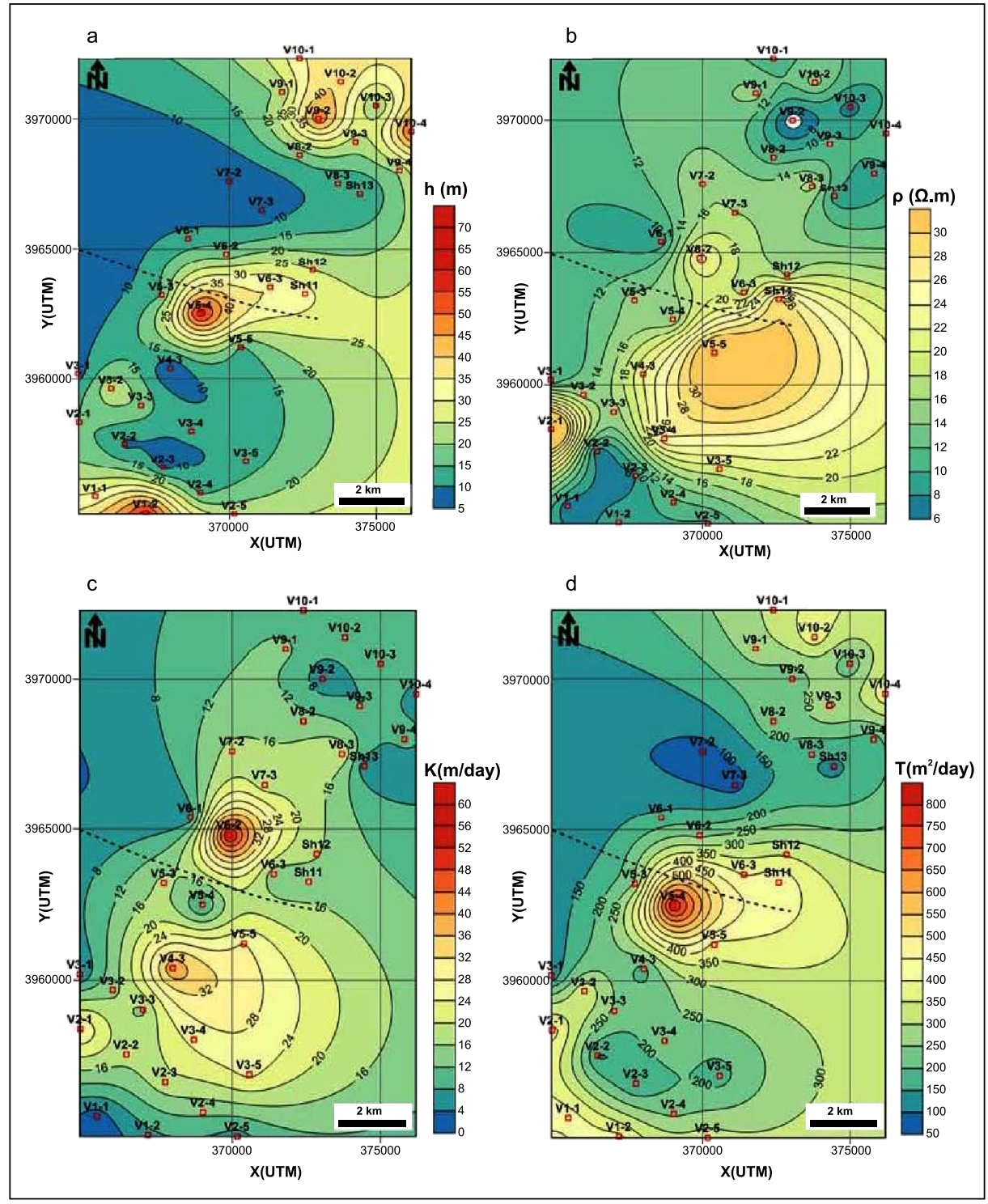

Fig. 10. a: Thickness of Quaternary aquifer $h$ in 34 VES locations in the study area, b: Resistivity $\rho$ of Quaternary aquifer in 34 VES locations in the study area, c: Hydraulic conductivity $K$ of Quaternary aquifer in 34 VES locations in the study area, d: Transmisivity $T$ of Quaternary aquifer in 34 VES locations in the study area. 
ternary aquifer at the totality of thirty four VES points in the Khanasser valley are summarized in the Table 4.

Table 4. Geophysical and hydrological parameters at 34 VES points for Quaternary aquifer in the Khanasser valley, Syria.

\begin{tabular}{|c|c|c|c|c|}
\hline & $\begin{array}{c}\boldsymbol{\rho}_{\text {rock }} \\
(\boldsymbol{\Omega . m})\end{array}$ & $\begin{array}{c}\boldsymbol{h} \\
(\mathbf{m})\end{array}$ & $\begin{array}{c}\boldsymbol{K} \\
(\mathbf{m} / \text { day })\end{array}$ & $\begin{array}{c}\boldsymbol{T} \\
\left(\mathbf{m}^{\mathbf{2}} / \text { day }\right)\end{array}$ \\
\hline Min & 4.3 & 4.5 & 1.55 & 78.66 \\
\hline Max & 43 & 59 & 54 & 814.2 \\
\hline Average & 14.8 & 22 & 15.24 & 277.65 \\
\hline SD & 8.5 & 15 & 10.97 & 143.58 \\
\hline
\end{tabular}

The high transmissivity and yields is related directly to the high thickness of alluvial gravels and sands, labelled as rammel aswad of the Quaternary aquifer in the Khanasser valley. The large differences and the drastic change in the productivity of wells is due to sharpen lateral and vertical variations of rammel aswad from place to place even in very short distances.

The transmissivity distribution obtained geophysically by applying the developed ANN approach for characterizing the Quaternary aquifer in the Khanasser valley is in a good agreement with the field hydrogeological observations. This proves the possibility of applying this technique to characterize the aquifer systems in the semi-arid regions worldwide.

\section{Conclusion}

A new alternative approach based on using both artificial neural network ANN technique and Vertical electrical sounding (VES) techniques is proposed to compute the hydraulic conductivity $K$ and the transmissivity $T$ of an aquifer.

We train a neural network in the VES locations, where available water samples exist to estimate the hydraulic conductivity and transmissivity. This trained neural network is required to extrapolate the hydraulic conductivity and transmissivity in the VES locations without water samples.

According to this ANN approach, the hydraulic conductivity and the transmissivity of the Quaternary aquifer in the Khanasser valley, Northern Syria are computed. We find an acceptable agreement between the hydraulic conductivity values obtained by the ANN approach and the real hydrolog- 
ical situation, obtained by the pumping test, which range between 0.864 and $8.64 \mathrm{~m} /$ day. The main advantage of ANN approach is the possibility to integrate VES measurements and pumping test, and no intermediate empirical relations are needed. ANN approach can provide a greater accuracy in predicting $K$ and $T$ if more pumping test were available, and it can be easily extended using additional input parameters as soil porosity and density which could potentially further increase the performance. The easy ANN approach is recommended to be extended for treating other hydrogeological problems related to semi-arid regions worldwide.

Acknowledgements. Authors would like to thank Dr. I. Othman, General Director of Syrian Atomic Energy Commission for permission to publish this research work. Cordial thanks are to the anonymous reviewers, particularly Prof. Norbert Péter Szabó for their suggestions, remarks and critics that considerably improve the final version of this paper.

\section{References}

ACSAD, 1984: Water resources map of the Arab countries. The Arab Center for the Studies of Arid Zones and Dry Lands, Damascus, Syria.

Archie E., 1942: The electrical resistivity log as an aid in determining some reservoir characterestics. Technical Publication 1422, Petroleum Technology. American Institute of Mining and Metallurgical Engineer, New York, USA, 8.

Arétouyap Z., Nouayou R., Njandjock Nouck P., Asfahani J., 2015: Aquifers productivity in the Pan-African context. J. Earth Syst. Sci., 124, 3, 527-539, Indian Academy of Sciences, doi : 10.1007/s12040-015-0561-1.

Arétouyap Z., Bisso D., Méli'i J. L., Njandjock Nouck P., Njoya A., Asfahani J., 2019a: Hydraulic parameters evaluation of the Pan-African aquifer by applying an alternative geoelectrical approach based on vertical electrical soundings. Geofís. Int., 58, 2, 113-126, doi: 10.22201/igeof.00167169p.2018.58.2.1964.

Arétouyap Z., Bisso D., Njandjock Nouck P., Amougou Menkpa L. E., Asfahani J., 2019b: Hydrogeophysical Characteristics of Pan-African Aquifer Specified Through an Alternative Approach Based on the Interpretation of Vertical Electrical Sounding Data in the Adamawa Region, Central Africa. Nat. Resour. Res., 28, 63-77, doi : 10.1007/s11053-018-9373-8.

Asfahani J., 2007a: Geoelectrical Investigation for Characterizing the Hydrogeological Conditions in Semi-arid Region in Khanasser Valley, Syria. J. Arid Environ., 68, 1, 31-52, doi: 10.1016/j.jaridenv.2006.03.028.

Asfahani J., 2007b: Neogene aquifer properties specified through the interpretation of electrical sounding data, Sallamiyeh region, central Syria. Hydrol. Process., 21, 21, 2934-2943, doi: 10.1002/hyp. 6510. 
Asfahani J., 2007c: Electrical Earth Resistivity surveying for delineating the characteristics of ground water in semiarid region in Khanaser Valley, Northern Syria. Hydrol. Process., 21, 8, 1085-1097, doi : 10.1002/hyp.6290.

Asfahani J., 2010a: Application of surfacial geoelectrical resistivity technique in hydrogeology domain for characterizing saline groundwater in semi arid regions. In: Veress B., Szigethy J. (Eds.): Horizons in Earth Science Research Series, Volume 1, NOVA Science Publishers, 351-381.

Asfahani J., 2010b: Electrical resistivity investigations for guiding and controling fresh water well drilling in semi arid region in Khanasser valley, Northern Syria. Acta Geophys., 59, 1, 139-154, doi: 10.2478/s11600-010-0031-8.

Asfahani J., 2013: Groundwater potential estimation using vertical electrical sounding measurements in the semi-arid Khanasser Valley region, Syria. Hydrol. Sci. J., 58, 2, 468-482, doi: 10.1080/02626667.2012.751109.

Asfahani J., 2016: Hydraulic parameters estimation by using an approach based on vertical electrical soundings (VES) in the semi-arid Khanasser valley region, Syria. J. Afr. Earth Sci., 117, 196-206, doi : 10.1016/j.jafrearsci.2016.01.018.

Basheer I. A., Hajmeer M., 2000: Artificial neural networks: Fundamentals computing design and application. J. Microbiol. Methods, 43, 1, 3-31, doi : 10.1016/S0167-7012 (00) 00201-3.

Dhakate R., Singh V. S., 2005: Estimation of hydraulic parameters from surface geophysical methods, Kaliapani Ultramafic Complex, Orissa, India. J. Environ. Hydrol., 13, paper 12 .

De Lima O. A. L., Niwas S., 2000: Estimation of hydraulic parameters of shaly sandstone aquifers from geological measurements. J. Hydrol., 235, 1-2, 12-26, doi : 10.1016/ S0022-1694(00) 00256-0.

Frohlich R. K., 1994: The electric-hydraulic relationship. A geophysical model. Trends in hydrogeology, 1, 347-358.

Frohlich R. K., Fisher J., Summerly E., 1996: Electric-hydraulic conductivity correlation in fractured crystaline bedrock: Central Landfill, Islande, USA. J. Appl. Geoph., 35, 4, 249-259, doi : 10.1016/0926-9851 (96)00028-6.

Heigold P. C., Gilkeson R. H., Cartwright K., Reed P. C., 1979: Aquifer transmissivity from surfacial electrical methods. Groundwater, 17, 4, 338-345, doi: 10.1111/j.17 45-6584.1979.tb03326.x.

Hoogeveen R. J. A., Zobisch M., 1999: Decline of groundwater quality in Khanasser valley (Syria) due to salt-water intrusion. In: Paper Presented at International Dryland Conference, Cairo, Egypt, p. 16.

Hornik K., Stinchcombe M., White H., 1989: Multilayer feedforward networks are universal approximators. Neural Netw., 2, 5, 359-366, doi : 10.1016/0893-6080(89) 900 20-8.

Hornik K., 1991: Approximation capabilities of multilayer feedforward networks. Neural Netw., 4, 2, 251-257, doi: 10.1016/0893-6080(91) 90009-T.

Lengiprovodkhoz Institute, 1987: Water resources in the Syrian desert, Syrian Arab Republic for pasture water supply. In: Hydrogeology. Moscow: USSR Ministry of Land Reclamation and Water Management, Volume 1, Book 2. 
Lesmes D., Friedman S. P., 2005: Relationships between the electrical and hydrogeological properties of rocks and soils. In: Rubin Y, Hubbard S. (Eds.): Hydrogeophysics. Water science and technology library, chapter 4, 50, 523, Springer, 87-128.

MATLAB, 2009: Neural Network Toolbox6 Users Guide.

Niwas S., De Lima O. A., 2003: Aquifer parameter estimation from surface resistivity data. Groundwater, 41, 1, 94-99, doi: 10.1111/j.1745-6584.2003.tb02572.x.

Ponikarov V. P., Mikhailov I. A., 1964: The Geological Map of Syria, 1:200,000 and Explanatory Notes. Moscow, USSR: V.O. Technoexport, Syrian Arab Republic, Ministry of Industry, Department of Geological and Mineral Research, Damascus, Syria.

Orellana E., Mooney H. M., 1966: Master Tables and curves for vertical electrical sounding over layered structures. Interciencia, Madrid, Spain.

Schweers W., Rieser A., Bruggeman A., Abu-Zakhem B., Asfahani J., Kadkoy N., Kasmo B., 2002: Assessment of groundwater resources for sustainable management in the Khanasser valley, northwest Syria. Paper presented at ACSAD/BGR Workshop on Soil and Groundwater Quality: Monitoring Management and Protection, Amman, 23-25 June 2002.

Salem H. S., 1999: Determination of fluid transmissivity and electric transverse resistance for shallow aquifers and deep reservoirs from surface and well-log electric measurments. Hydrol. Earth Syst. Sci., 3, 3, 421-427, doi: 10.5194/hess-3-421-1999.

Salem H. S., 2001: Modeling of lithology and hydraulic conductivity of shallow sediments from resistivity measurements using Schlumberger vertical electrical soundings. Energy Sources, 23, 7, 599-618, doi: 10.1080/00908310119202.

Soumi G., 1991: Supplemental Irrigation Systems of the Syrian Arab Republic (SAR). In: Perrier E. R., Salkini, A. B. (Eds.): Supplemental Irrigation in the Near East and North Africa. Proceeding of a Workshop on Regional Consultation on Supplemental Irrigation. ICARDA and FAO, 7-9 December 1987, Rabat, Morocco, Kluwer Academic Publishers, Dordrecht, The Netherlands, 497-511.

Yadav G. S., Abolfazli H., 1998: Geoelectrical soundings and their relationship to hydraulic parameters in semi arid regions of Jalore, Northwestern India. J. Appl. Geoph., 39, 1, 35-51, doi: 10.1016/S0926-9851(98)00003-2.

Zohdy A. A. R., 1989: A new method for the automatic interpretation of Schlumberger and Wenner sounding curves. Geophysics, 54, 2, 245-253, doi : 10.1190/1.1442648.

Zohdy A. A. R., Bisdorf R. J., 1989: Schlumberger Sounding Data Processing and Interpretation Program. U.S. Geological Survey, Denver. 